\title{
Groundwater Tracing in Orion, Marion and Eyota Townships of Olmsted County, Minnesota
}

Larsen, Martin R.'1, Green, Jeffrey A.', Wheeler, Betty J.3., Kasahara, Sophie M.3., Alexander, E. Calvin, Jr. ${ }^{3}$

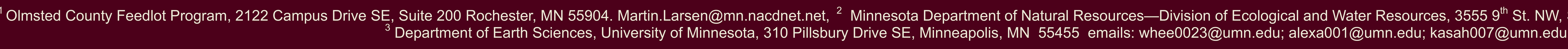

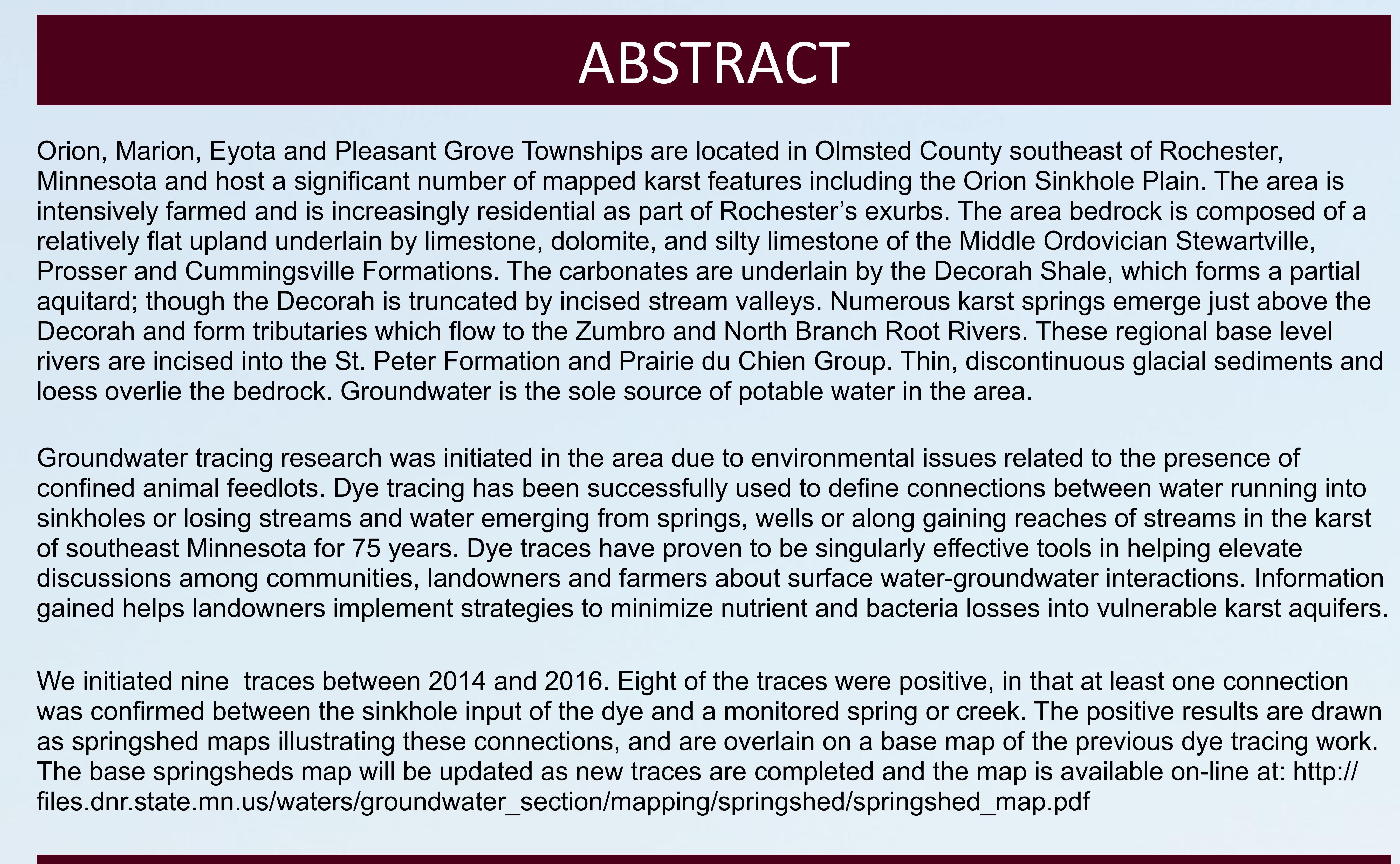

BACKGROUND

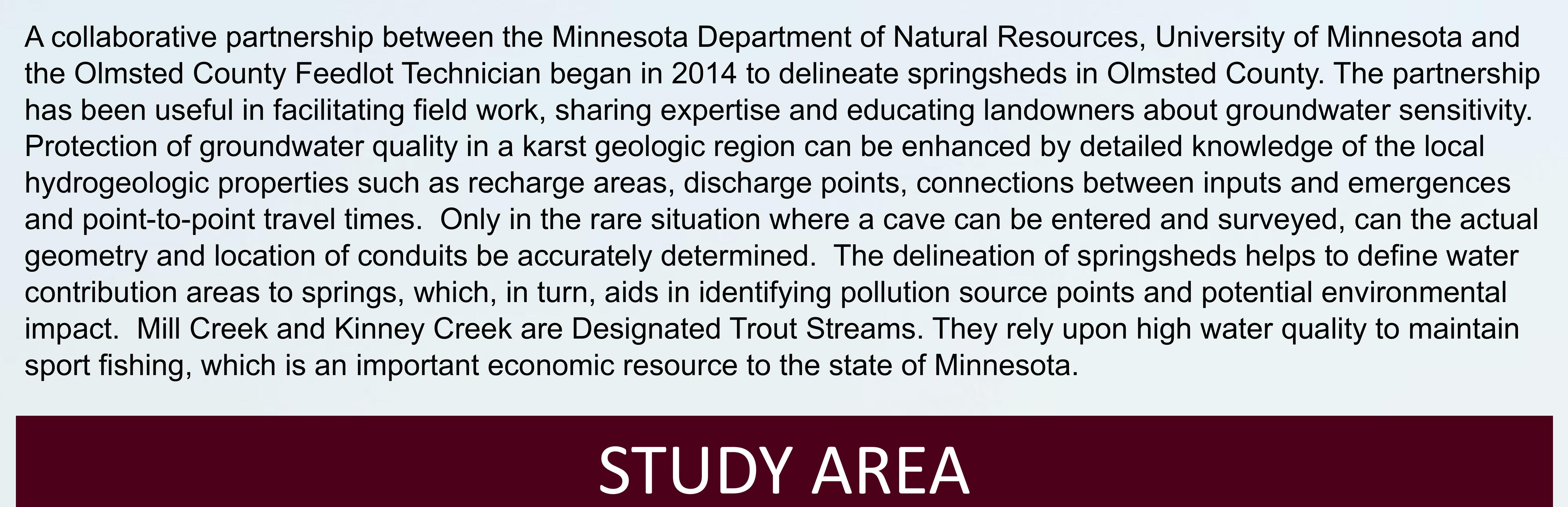

Alarge array of sinkholes known as the Orion Sinkhole Plain (Picture 1) is I located south of interstate 90 and noth of

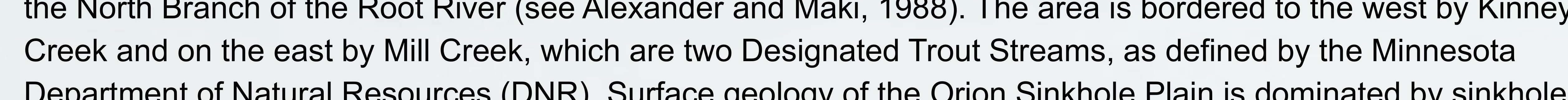

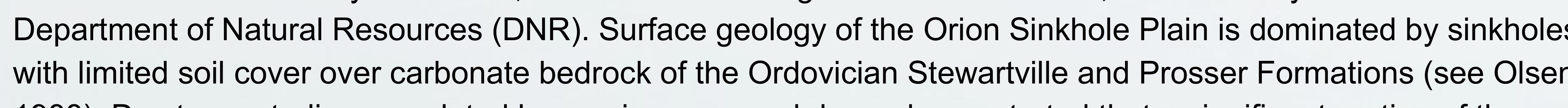

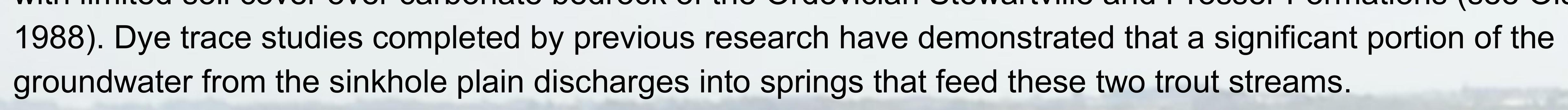

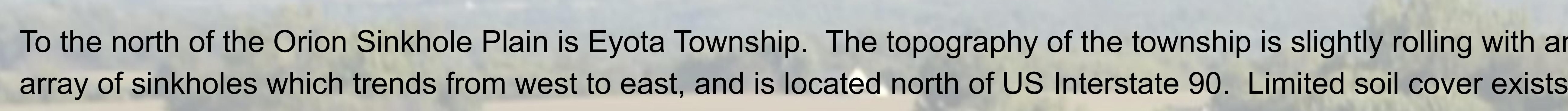

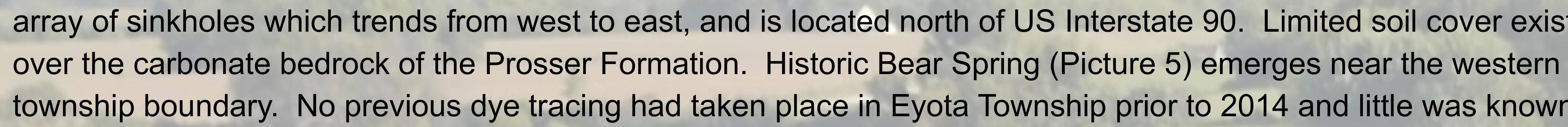
about the groundwater flow paths. Specific iniection points were chosen based on known
contanination events or where previous dye traces had $n$ al been conducteded Seven dye iniection points are in locations
where the Prosser formation of the Galena aroup is the

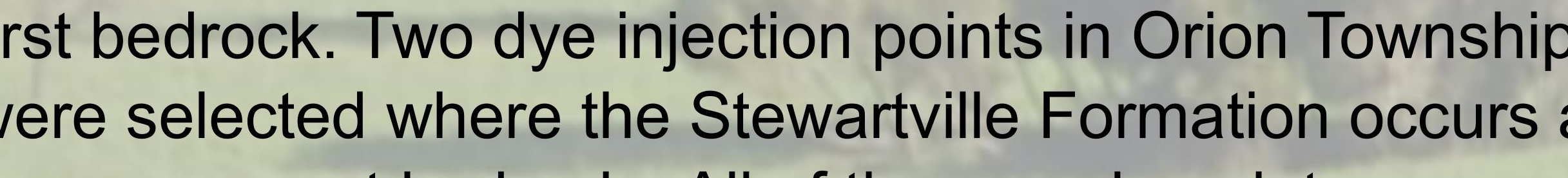

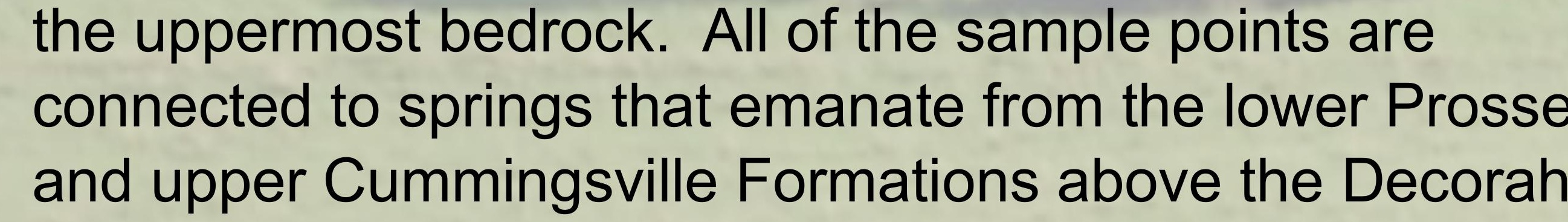
and upper Cumn
Shale Formation. Picture 1. Orion Sinkhole Plain (Photo by Martin
arsen,

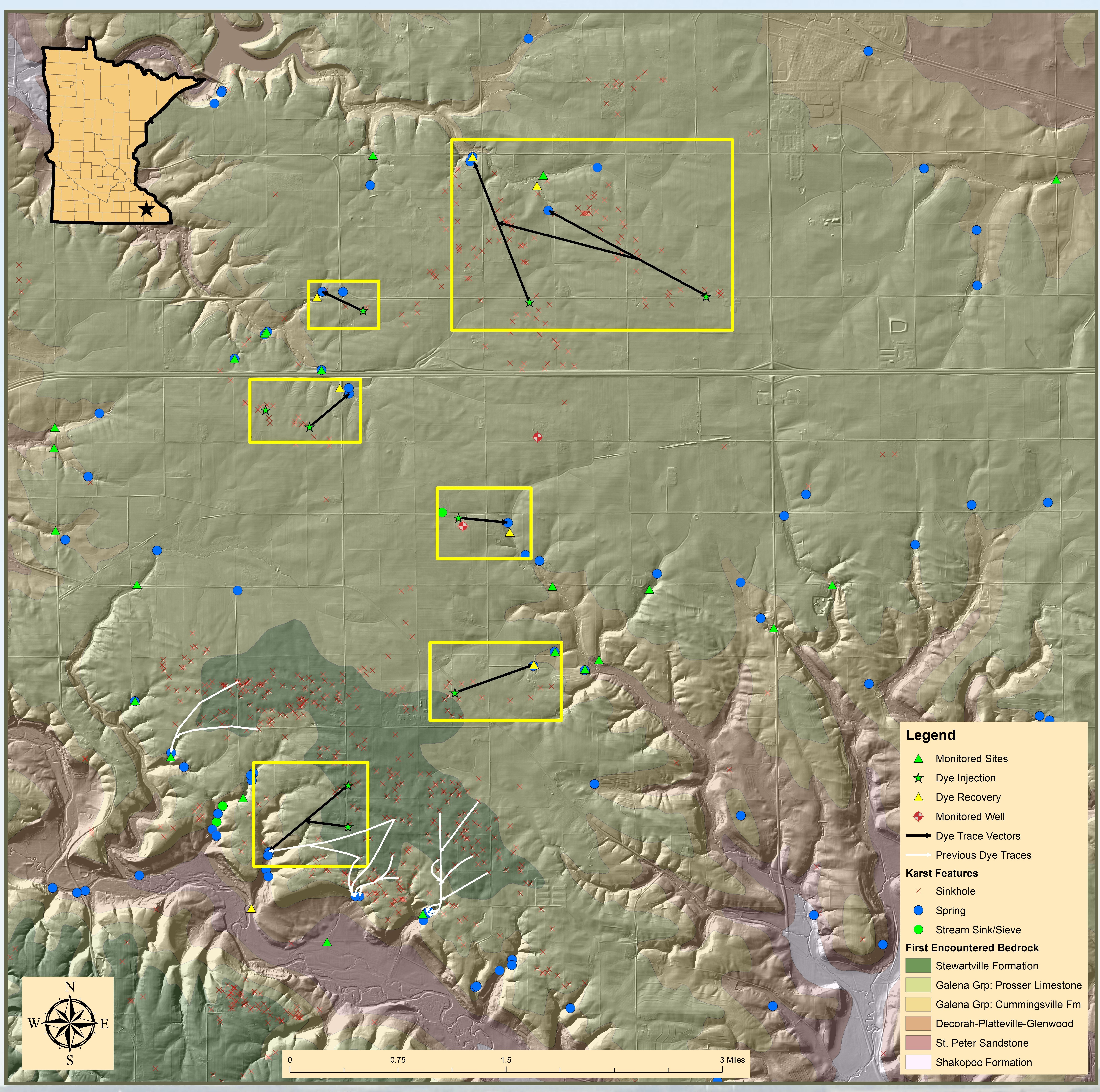

Figure 1. Groundwater Flow Paths and Dye Trace Vectors.

\section{METHODS}

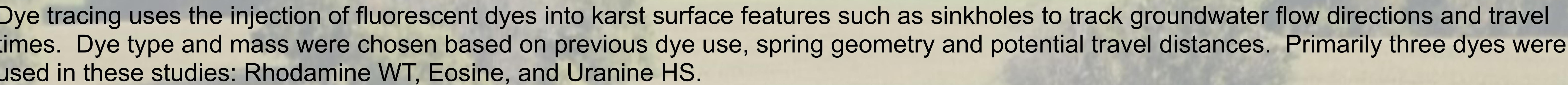
Prior to injection, charcoal packet detectors (bugs) were placed in the identified springs, or in spring runs downstream of the identified springs,

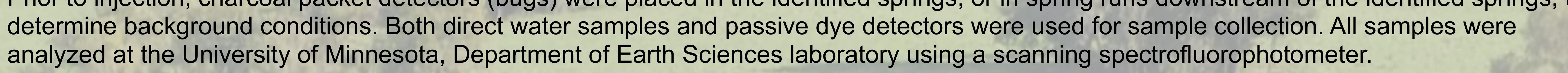

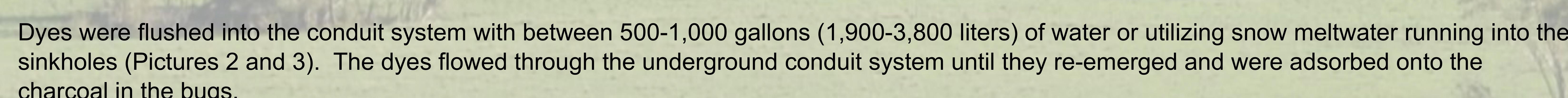
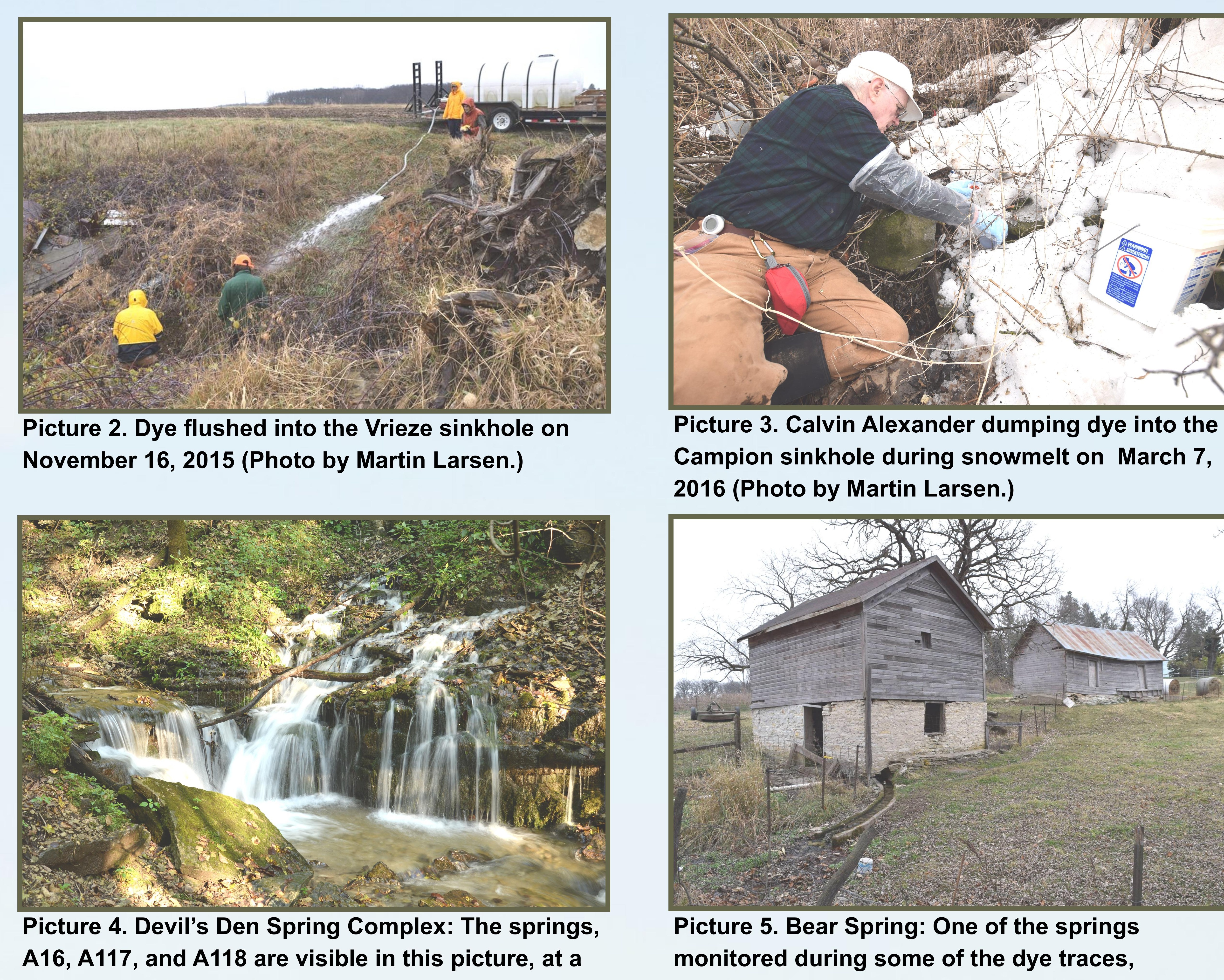
2016 (Photo by Martin Larsen.)

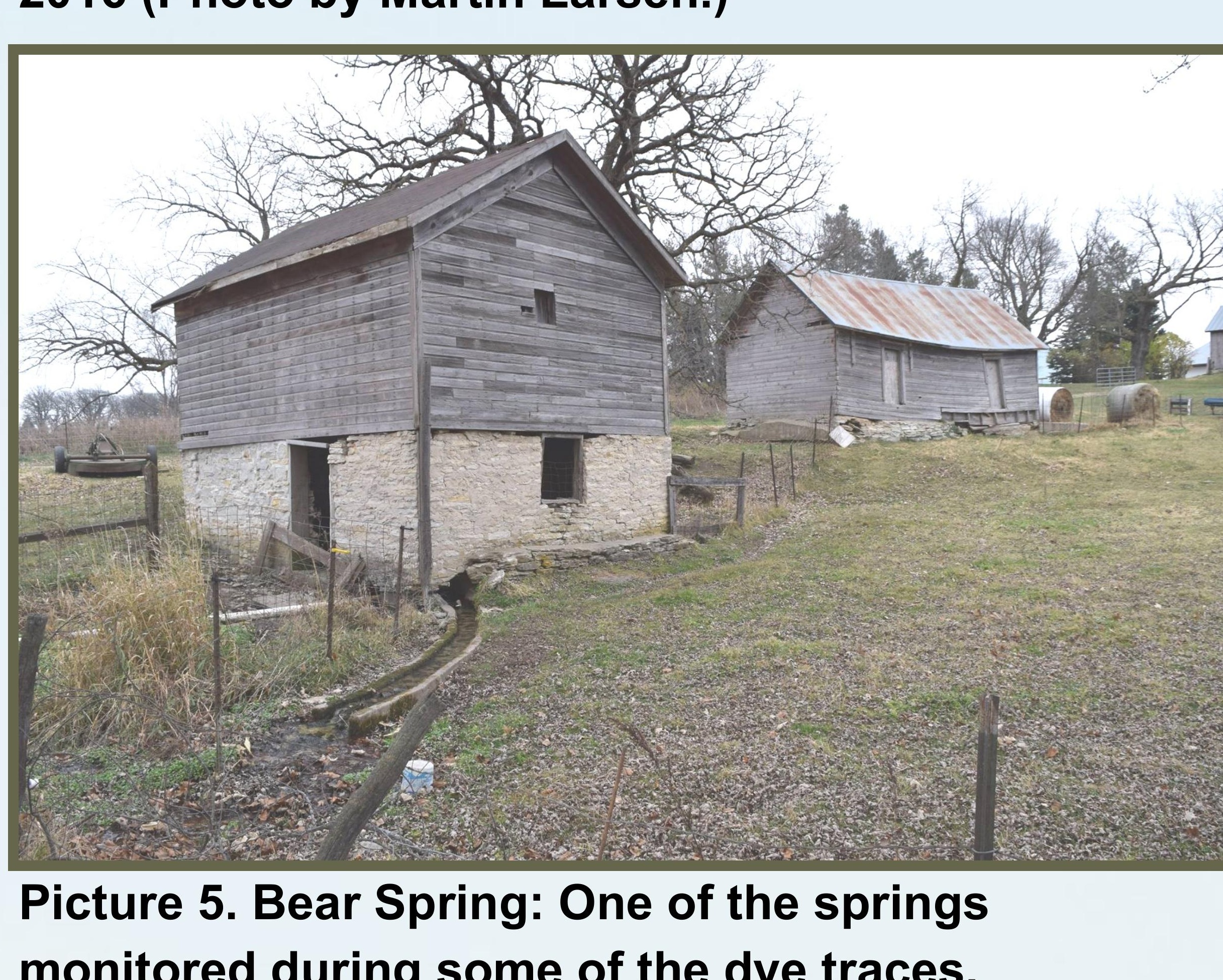
time when flow was running high. The springs were emanates from the hillside within the old spring Separately mon
Martin Larsen.)

RESULTS

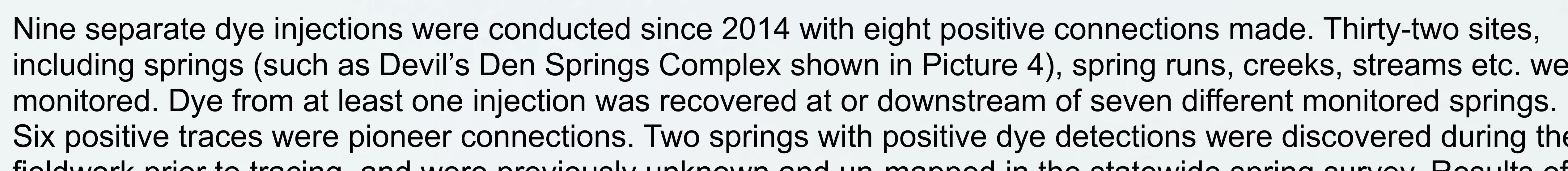

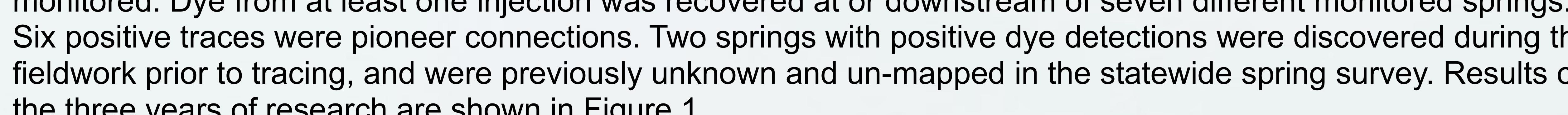

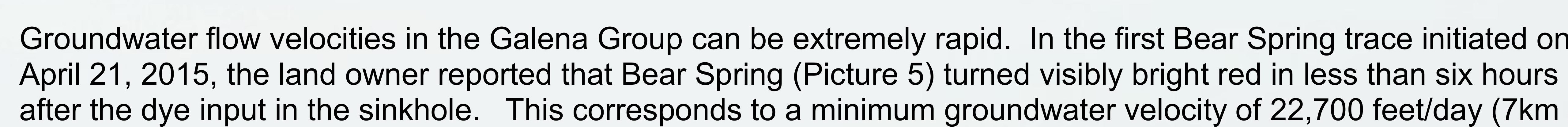

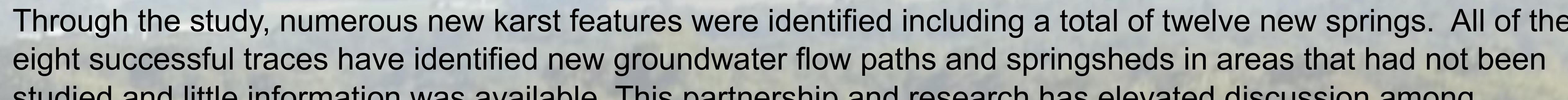

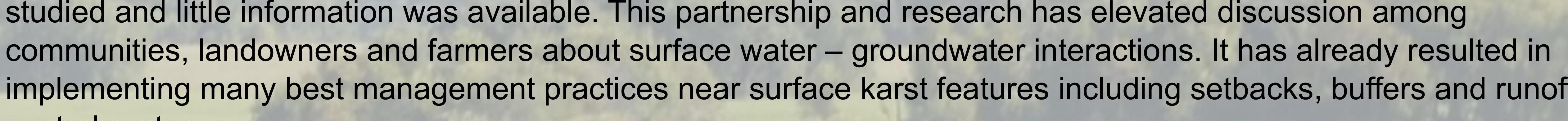

REFERENCES

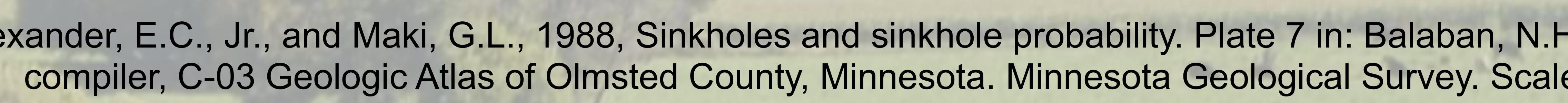

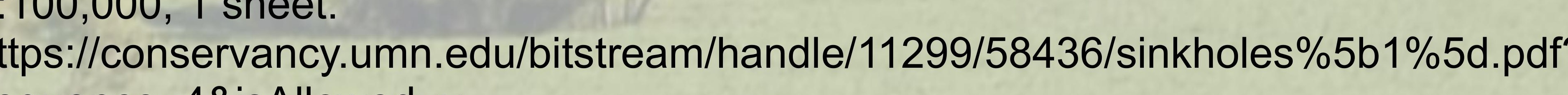
sequence=-4isistliowed=y

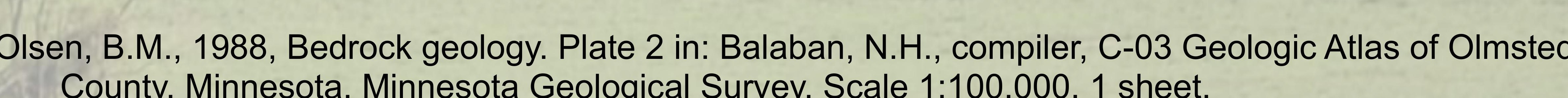

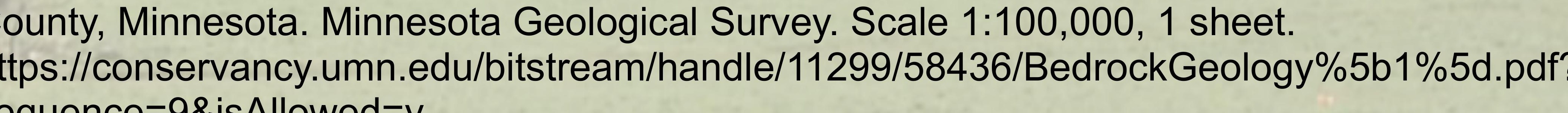

